\title{
Exploring the Effectiveness of Mandatory Premarital Screening and Genetic Counselling Programmes for $\beta$-Thalassaemia in the Middle East: A Scoping Review
}

\author{
Marwa Saffi ${ }^{a}$ Natasha Howard ${ }^{b}$ \\ ${ }^{a}$ Disease Prevention and Screening Centres, Ambulatory Healthcare Services, Abu Dhabi \\ Health Services Company (SEHA), Abu Dhabi, United Arab Emirates; ${ }^{\text {b } F a c u l t y ~ o f ~ P u b l i c ~ H e a l t h ~ a n d ~ P o l i c y, ~}$ \\ London School of Hygiene and Tropical Medicine, London, UK
}

\section{Key Words}

Premarital screening · Genetic counselling $\cdot \beta$-Thalassaemia . Reproductive rights · Middle East

\begin{abstract}
Background: $\beta$-Thalassaemia is a common genetic blood disorder in the Middle Eastern region. Mandatory premarital screening and genetic counselling (PMSGC) programmes are implemented in 8 Middle East countries to reduce at-risk marriages and thus disease prevalence. A scoping review was conducted to explore the effectiveness of these programmes. Methods: The 6-stage scoping framework of Arksey and O'Malley [Int J Soc Res Methodol 2005;8:19-32] was used. Reported outcomes were analysed per country, with success defined as achieving a $65 \%$ reduction in at-risk marriages and/or thalassaemia-affected births. Emergent enablers and barriers were analysed thematically. Results: Twenty-one sources were included from the 1,348 identified, discussing 7 country programmes, with 95\% (20/21) published during 2003-2013. Five publications each were included for Iran and Saudi Arabia, 3 for Turkey, 2 each for Bahrain and Iraq (Kurdistan), and 1 for the United Arab Emirates, plus 2 multi-country evaluations. No programme
\end{abstract}

achieved a $65 \%$ at-risk marriage cancellation rate. Though data on thalassaemia-affected birth reductions were minimal, programmes in Iran, Turkey and Iraq reported at least $65 \%$ reductions. A thematic analysis found that screening timing, access to prenatal detection and abortion, socio-religious issues, awareness and counselling affected decisions. Conclusion: This review found that PMSGC programmes were unsuccessful in discouraging at-risk marriages but successful in reducing the prevalence of affected births in countries providing prenatal detection and therapeutic abortion. A life cycle approach to prevention, incorporation of school screening, awareness campaigns, reconsideration of therapeutic abortion, and screening and counselling of couples married prior to programme inception are likely to improve the effectiveness of such programmes in the Middle Eastern region.

(C) 2015 S. Karger AG, Basel

\section{Introduction}

$\beta$-Thalassaemia is a single-gene inherited haemoglobinopathy characterised by a decreased production of globin chains, resulting in chronic anaemia and skeletal

\section{KARGER 125}

(c) 2015 S. Karger AG, Base

$1662-4246 / 15 / 0184-0193 \$ 39.50 / 0$

E-Mail karger@karger.com

www.karger.com/phg
Natasha Howard

Faculty of Public Health and Policy

London School of Hygiene and Tropical Medicine

15-17 Tavistock Place, London WC1H 9SH (UK)

E-Mail natasha.howard@lshtm.ac.uk 
and organ deformities. The World Health Organization (WHO) estimates that $\beta$-thalassaemia affects $2.9 \%$ of the world's population, creating a major public health problem that burdens health care systems and significantly impacts the quality of life of the affected patients [1]. The survival of individuals with $\beta$-thalassaemia major is reliant on monthly blood transfusions and iron chelation therapy [2]. Without blood transfusions, death usually occurs within the first few years of life. The average life expectancy of those with $\beta$-thalassaemia major is 32 years, and much shorter if untreated [3]. Additionally, regular blood transfusions may cause iron overload, leading to progressive cardiac damage and death [4]. Many $\beta$-thalassaemia patients in the Middle East progress to advanced stages within a few years of diagnosis due to an inadequate supportive infrastructure [5]. The only treatment for $\beta$-thalassaemia is bone marrow transplantation, which is expensive and risky; moreover, it is difficult to identify a suitable donor, and the required infrastructure is unavailable in most Middle Eastern countries. The cost of blood transfusions for $\beta$-thalassaemia major patients in the Middle East has been estimated at USD 3,200 annually per patient, with lifetime costs of approximately USD $284,145[6,7] . \beta$-Thalassaemia is inherited, and couples where both partners are carriers (i.e. at-risk couples) have a 1 -in- 4 chance of having a child with $\beta$-thalassaemia major.

The prevalence of $\beta$-thalassaemia is high in the Middle East, where $1-15 \%$ of the population carries the trait $[5,8]$. A major contributor to the high $\beta$-thalassaemia prevalence in the Middle East is the high prevalence (25$60 \%$ ) of consanguineous marriages, particularly among first cousins [9]. Consanguineous or common-ancestry marriages increase the chances of offspring inheriting disease traits, with closer consanguineous relationships at an increased risk [10]. Consanguineous marriages are socially favoured in many Arab majority countries [9]. Sociological studies indicate that they increase the couple's stability due to compatibility between the husband, the wife and the in-laws, strengthen family ties and solidarity, support the transmission of shared values and ease premarital negotiations particularly by allowing wealth and property to remain within the family [11]. A study in Egypt found that men with educational and occupational status were considered 'valuable assets' and pressured to marry within the family [3]. Consanguinity predates Islam, and the Qur'an does not encourage the practice [11].

Due the high burden $\beta$-thalassaemia places on patients, families and health care systems in the Middle East,
Table 1. Countries in the Mediterranean and Middle East regions with mandatory PMSGC programmes, by implementation year

\begin{tabular}{ll}
\hline Region & Implementation year \\
\hline Mediterranean & \\
$\quad$ Cyprus & 1973 \\
$\quad$ Italy & 1975 \\
$\quad$ Greece & 1975 \\
Middle East & \\
Turkey & 1995 \\
Iran & 1997 \\
Palestinian territories & 2000 \\
Jordan & 2004 \\
Saudi Arabia & 2004 \\
Bahrain & 2005 \\
Iraqi Kurdistan & 2008 \\
United Arab Emirates & 2011 \\
\hline
\end{tabular}

Adapted from Alswaidi and O’Brien [10] and Cousens et al. [12].

the WHO advocates prevention and reduction of the burden of $\beta$-thalassaemia through voluntary genetic screening [12]. In Iran, the total costs of preventing 1 case of $\beta$-thalassaemia were estimated at USD 100, less than the cost of a single year of optimum support for a case of $\beta$-thalassaemia [13]. Similar findings in Cyprus and Greece indicated that the cost of prevention was equal to that of treating 1 affected newborn for 1 year, while the annual cost of the screening programme was equivalent to treating the thalassaemia-affected population for 1 week [3]. Prevention thus appears to be significantly more cost effective while reducing the psychosocial implications of this chronic disease [7].

Premarital screening and genetic counselling (PMSGC), popular in the Middle East as it is religiously and socially unacceptable to bear children outside of marriage, aims to identify $\beta$-thalassaemia carriers among couples planning to marry [2]. Genetic counselling is provided to atrisk couples to ensure they understand the reproductive risks and available options [4]. PMSGC programmes aim to reduce $\beta$-thalassaemia births through: (i) prevention of at-risk marriages by discouragement during counselling and, where legal, (ii) termination of affected foetuses through prenatal diagnosis (PND) and therapeutic abortion. Alswaidi and O'Brian [10] suggested that screening could reduce the $\beta$-thalassaemia burden by reducing atrisk marriages and preventing up to $95 \%$ of affected births. 
Table 2. Grounds for legal abortion in Middle Eastern countries with mandatory PMSGC programmes

\begin{tabular}{|c|c|c|c|c|c|c|c|}
\hline & $\begin{array}{l}\text { To save the } \\
\text { woman's life }\end{array}$ & $\begin{array}{l}\text { To preserve the } \\
\text { woman's } \\
\text { physical health }\end{array}$ & $\begin{array}{l}\text { To preserve the } \\
\text { woman's } \\
\text { mental health }\end{array}$ & $\begin{array}{l}\text { Rape or } \\
\text { incest cases }\end{array}$ & $\begin{array}{l}\text { Foetal } \\
\text { impairment }\end{array}$ & $\begin{array}{l}\text { Economic or } \\
\text { social cases }\end{array}$ & On request \\
\hline Iran & $\checkmark$ & - & - & - & $\checkmark$ & - & - \\
\hline Iraq & $\checkmark$ & - & - & - & $\checkmark$ & - & - \\
\hline Saudi Arabia & $\checkmark$ & $\checkmark$ & $\checkmark$ & - & - & - & - \\
\hline Turkey & $\checkmark$ & $\checkmark$ & $\checkmark$ & $\checkmark$ & $\checkmark$ & $\checkmark$ & $\checkmark$ \\
\hline United Arab Emirates & $\checkmark$ & $\checkmark$ & $\checkmark$ & - & - & - & - \\
\hline
\end{tabular}

Source: UN Department of Economic and Social Affairs [34]. $\checkmark=$ The reasons listed are used as grounds for legal abortion in the countries listed; $-=$ no data available.

Several countries in the Mediterranean and Middle Eastern regions have implemented mandatory PMSGC programmes to reduce the prevalence of genetic disorders [4]. Mandatory PMSGC programmes began in the 1970 s to eradicate $\beta$-thalassaemia in the Mediterranean region (table 1). Cyprus was first in 1973 and very successful, decreasing the number of affected births from 51 to 8 annually between 1974 and 1979 and to 0 since 2002 [12]. Similar programmes were implemented in Italy and Greece, also achieving 100\% $\beta$-thalassaemia birth reductions $[12,14]$. As less than $5 \%$ of the reductions were attributed to separation of engaged couples, success was linked to the provision of free PND and the availability of abortion, effective education and counselling $[3,15]$.

Mediterranean successes created an approach for the Middle East that foundered with the illegality of therapeutic abortion in several countries (table 2). Abortion is restricted by nearly all major world religions, including Islam. Scholars from the 4 Sunni and the Shiite schools agree that abortion may be performed to save the mother's life, but they disagree over the status of the foetus before 4 months of gestation. While Muslim scholars have differing opinions on abortion, all have agreed that the human 'spirit' enters the body at 4 months of gestation (120 days), at which point the foetus is 'another creation' according to Islamic metaphysics (Qur'an 23:14) and abortion is forbidden unless the life of the mother is threatened [16]. In 1990, the Islamic Jurisprudence Council of the World Islamic League in Mecca issued a fatwa (Islamic legal ruling) allowing for select termination of pregnancies if a committee of physicians determined that the foetus was severely malformed and its birth would have seriously negative effects on itself and its family [3]. The Organization of Islamic Conference - an organisation of countries with Muslim majorities or pluralities has 57 members, 12 of whom allow unrestricted access to abortion. With the exception of Turkey and Tunisia, these are mainly former Soviet Bloc states. Bahrain, a politically and socially conservative Muslim state, is the 12th to permit unrestricted abortion. Among socially conservative Muslim countries, 7 permit abortion in the first 4 months for foetal deformities, with 4 of these in sub-Saharan Africa (i.e. Benin, Burkina Faso, Chad and Guinea) and 3 in the Middle East (i.e. Iran, Kuwait and Qatar) [16]. In countries where abortion for foetal impairment is illegal (i.e. Jordan, Saudi Arabia and the United Arab Emirates), mandatory PMSGC programmes aim to reduce the prevalence of $\beta$-thalassaemia through genetic counselling to discourage at-risk marriages. Countries offering PND and abortion aim to reduce $\beta$-thalassaemia prevalence by discouraging at-risk marriages and terminating affected pregnancies.

\section{Aim and Objectives}

This review aimed to explore the outcomes of mandatory PMSGC programmes for $\beta$-thalassaemia in the Middle Eastern region. Its objectives were to: (i) summarise the nature of the literature; (ii) discuss programme effectiveness in reducing at-risk marriages and $\beta$-thalassaemia births, and (iii) identify barriers and enablers to programme effectiveness in the Middle East. 


\section{Methods}

A scoping review was conducted using the 6-page methodological framework of Arksey and O'Malley [17], adapting the revisions of Levac et al. [18].

\section{Identifying the Research Question}

Authors selected the research question 'Are PMSGC programmes in the Middle East associated with successful reductions in at-risk marriages or $\beta$-thalassaemia births?' For this review, programme success was defined as at least a $65 \%$ at-risk marriage cancellation rate, or a $65 \%$ reduction in $\beta$-thalassaemia birth incidence, after programme implementation. These levels were selected after consultation with regional experts as being high enough to have a significant impact on $\beta$-thalassaemia responses while still low enough to be achievable by most programmes if the PMSGC model was effective.

\section{Identifying Relevant Work}

Multiple literature sources were searched to increase comprehensiveness [17]. First, the electronic databases PubMed, MEDLINE, ScienceDirect and Embase were searched systematically using the key terms 'genetic, premarital, haemoglobinopath*, thalassemia, $\beta$-thalassemi*, genetic abnormalit*, genetic disorder*, haemoglobinopath*' AND 'screen*' OR 'counsel*' OR 'evaluat*, effect*, outcome*, accept*, decision*, prevent*, marr*'. Second, the database OpenGray was searched systematically, using the same keywords, for unpublished literature and a Google Scholar search for 'premarital screening and $\beta$-thalassemia' was conducted. Third, the key genetics journals European Journal of Human Genetics, Public Health Genomics, Journal of Medical Genetics and Genetic Epidemiology were purposively hand searched. Finally, websites of the United Nations and civil-society organisations UNICEF (United Nations Children's Fund), WHO, Thalassemia International Federation, UAE Genetic Disease Association and Emirates Thalassemia Society were purposively searched for studies, reports and conference proceedings. Relevant citations were snowballed to identify further relevant sources.

\section{Source Selection}

To ensure relevance, inclusion criteria were primary or secondary research on outcomes of PMSGC programmes for genetic diseases implemented in countries within the Middle Eastern region published in English from 2000 onwards. The first author screened the title, the abstract, and then the full text against the criteria. After removal of duplicates, the remaining sources were checked against the exclusion criteria (i.e. no English abstract, no full text available, not implemented in a Middle Eastern country, not specific to $\beta$-thalassaemia, not a mandatory programme and no discussion of programme outcomes) and removed if they met at least one. The remaining sources were charted.

\section{Data Charting}

Data for each source were charted using the following headings: source authors, publication year, source title, type of search (e.g. database or hand search), country, study design, study participants, programme description, availability of PND, legal status of abortion, main findings and conclusions. The first author was primarily responsible for data extraction with support from the second author.
Collating, Summarising and Reporting

The nature and distribution of the studies were summarised in accordance with the research question. Potential contributors to programme success that emerged from the thematic analysis were reported.

\section{Stakeholder Consultation}

A stakeholder group was organised to provide feedback on preliminary results. Seven experts were contacted via telephone, and 6 agreed to participate. Stakeholders reviewed a draft of the results section and provided feedback on potential additional sources, any obvious gaps or unexpected findings, how best to display findings, and policy or practice recommendations that could inform the discussion section.

Ethics

Ethical approval, though not required for a review, was provided by the Research Ethics Committee of the London School of Hygiene and Tropical Medicine (approval No. 8272).

\section{Results}

\section{Extent, Distribution and Nature of the Literature}

Figure 1 provides a flow diagram of the 21 sources included from the 1,358 identified. Most sources (6/21; $29 \%$ ) were published in 2013 . Two sources included several country programmes $[10,12]$. Iran and Saudi Arabia were best represented with 5 (24\%) sources each, followed by Turkey with 3 (14\%), Bahrain and Iraq with 2 (10\%) each, Jordan and the United Arab Emirates with 1 (5\%) each, and none for the Palestinian territories. Approximately half (11/21) were retrospective reviews, 4 were cohort studies, and 3 each were case-control and crosssectional studies.

\section{Programme Effectiveness}

Literature from 6 countries (i.e. Bahrain, Iran, Iraqi Kurdistan, Jordan, Saudi Arabia and Turkey) included indicators of programme effectiveness, shown in table 3 $[1,4,10,12-14,19-27]$. One source reviewing the United Arab Emirates programme included satisfaction surveys and recommendations but provided no statistics [8].

\section{Bahrain}

The PMSGC programme was mandated in 2004, and PND and therapeutic abortion are legal. A cross-sectional study of 1,070 PMSGC attendees reported a $43.3 \%$ atrisk marriage cancellation rate [23]. No analysis of changes in $\beta$-thalassaemia incidence rates in Bahrain was found in the literature. 


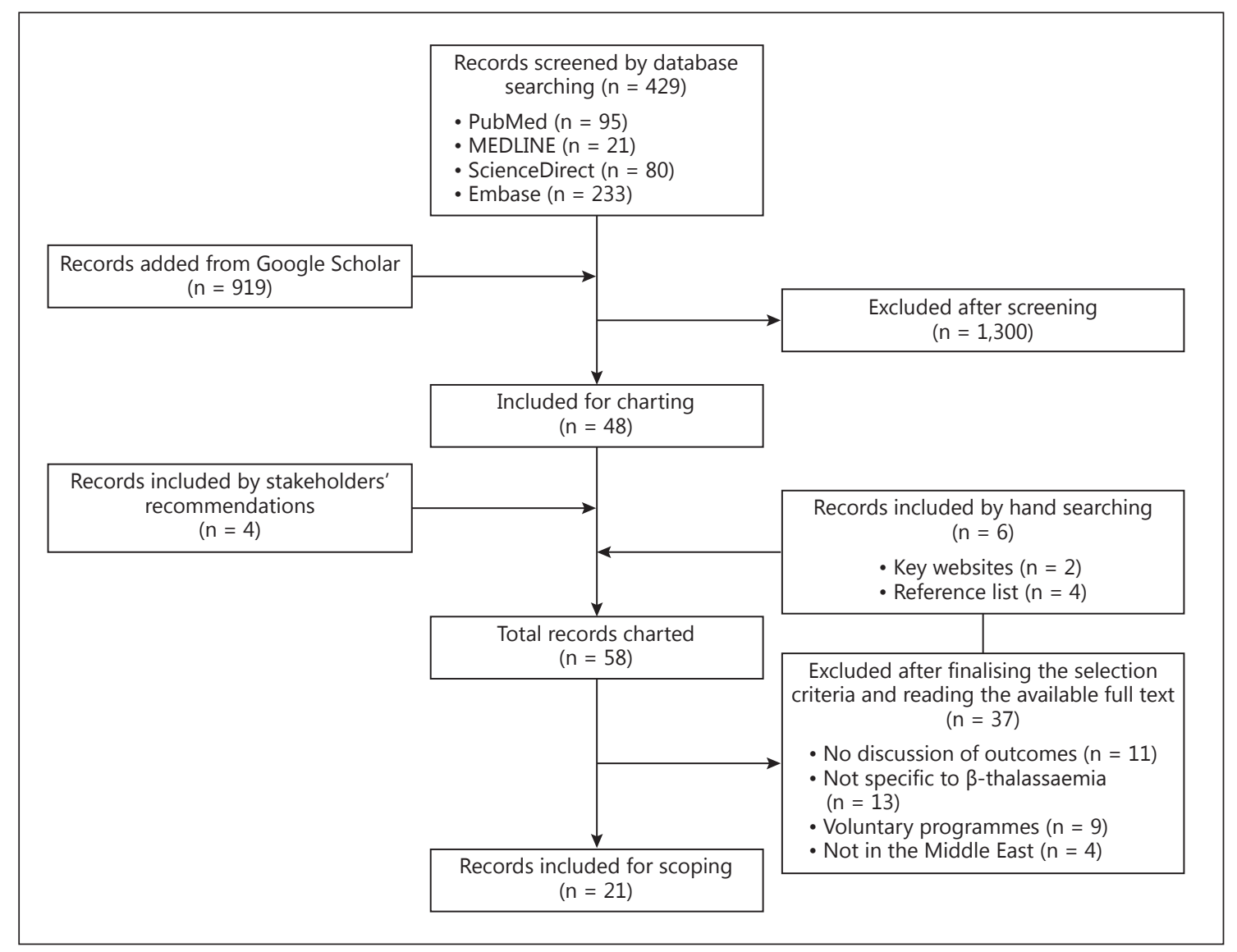

Fig. 1. Selection of the records included in this scoping review.

Table 3. Programme effectiveness

\begin{tabular}{|c|c|c|c|c|c|}
\hline \multirow[t]{2}{*}{ Country } & \multirow[t]{2}{*}{$\begin{array}{l}\text { Implementation } \\
\text { year }\end{array}$} & \multicolumn{2}{|c|}{$\begin{array}{l}\text { Availability of additional } \\
\text { services }\end{array}$} & \multicolumn{2}{|l|}{ Effectiveness } \\
\hline & & PND & abortion & $\begin{array}{l}\text { at-risk marriage } \\
\text { cancellation, } \%\end{array}$ & $\begin{array}{l}\text { at-risk birth } \\
\text { reduction, } \%\end{array}$ \\
\hline \multicolumn{6}{|l|}{ Mediterranean } \\
\hline Cyprus & 1973 & $\checkmark$ & $\checkmark$ & $<5$ & 100 \\
\hline Italy & 1975 & $\checkmark$ & $\checkmark$ & $<5$ & 100 \\
\hline Greece & 1975 & $\checkmark$ & $\checkmark$ & $<5$ & 100 \\
\hline \multicolumn{6}{|l|}{ Middle East } \\
\hline Turkey & $1995 / 1998$ & $\checkmark$ & $\checkmark$ & 13 & 90 \\
\hline Iran & 1997 & $\checkmark$ & $\checkmark$ & 53 & 80 \\
\hline Palestinian territories & 2000 & $\mathrm{x}$ & $\mathrm{x}$ & - & - \\
\hline Jordan & 2004 & $\checkmark$ & $\mathrm{x}$ & 40 & - \\
\hline Saudi Arabia & 2004 & $\mathrm{x}$ & $\mathrm{x}$ & 10 & - \\
\hline Bahrain & 2005 & $\checkmark$ & $\checkmark$ & 58 & - \\
\hline Iraqi Kurdistan & 2008 & $\checkmark$ & $\checkmark$ & 2 & 65 \\
\hline United Arab Emirates & 2011 & $\mathrm{x}$ & $\mathrm{x}$ & - & - \\
\hline
\end{tabular}

$\checkmark=$ Service is available; $\mathrm{x}=$ service is not available/accessible; $-=$ no data. 
Iran

In 1997, PMSGC became mandatory in the Islamic Republic of Iran and included PMSGC for carrier couples found at risk of having $\beta$-thalassaemia-affected children [13]. Iran is the only Islamic Republic whose legal system is founded solely on Shiite shari'a (Islamic law), and the first contemporary Islamic country attempting to combine principles of theocracy and religious law with representative, parliamentary democracy. Iran serves as a model, politically, socially, and religiously through its seminaries, for other Shiite countries (e.g. Iraq) and Shiite minorities in Sunni majority countries (e.g. Bahrain, Kuwait and Lebanon). In 2003, the addition of PND initiated reforms in abortion-related laws. While abortion for any reason other than saving the mother's life was illegal in Iran, Islamic clergies declared a fatwa permitting the abortion of homozygote $\beta$-thalassaemia foetuses up to 16 weeks of gestational age [13]. Prior to adding PND, genetic counselling aimed to convince at-risk couples not to marry [19].

Evaluation in West Azerbaijan Province found that $53 \%$ of marriages among at-risk couples during 2002 2006 were cancelled after screening [13]. Similarly, Cousens et al. [12] noted that, prior to the provision of PND and pregnancy termination in Iran, about half of at-risk couples identified by premarital screening proceeded to marriage. Lower cancellation rates, averaging 19.4\%, were found in Central Iran in 1995-2010 [19]. Ahmadnezhad et al. [13] reported an increase in West Azerbaijan from 38\% in 2003 to 69\% in 2006. Zeinalian et al. [19] found decreased marriage cancellations in Central Iran, from 50.4\% in 1997 to $9.4 \%$ in 2010, and a significantly increased PND uptake, from 7 couples in 2003 when it was legalised to 560 in 2010. In Southern Iran, 292 couples underwent PND between 2002 and 2004, resulting in the detection and termination of 69 thalassaemia-affected foetuses [14]. In West Azerbaijan, 92 thalassaemia-affected foetuses were terminated in 2005-2010, and thus $70 \%$ of $\beta$-thalassaemia births over 10 years occurred within the first 5 years of the programme before the availability of PND and legal abortion. The uptake of PND among at-risk couples increased from $2.8 \%$ in 2003 to $85 \%$ in 2010 , leading to an estimated 1,000 fewer $\beta$-thalassaemia births annually [19].

The prevalence of $\beta$-thalassaemia births in Southern Iran decreased by $81.1 \%$, from 2.53/1,000 births in 1995 to $0.82 / 1,000$ births in 2004 [14]. The incidence of $\beta$-thalassaemia decreased by $96.5 \%$ over 10 years in Central Iran, from 43.7/100,000 in 1997 to $1.5 / 100,000$ in
2010 [19]. Iran's successful $\beta$-thalassaemia reduction placed the Iranian PMSGC programme as a benchmark for other national programmes.

\section{Iraqi Kurdistan}

The PMSGC programme was mandated in 2008 in Kurdistan, Northern Iraq, with PND and therapeutic abortion available. In the first 3 years (2008-2010), 91\% of at-risk couples proceeded with marriage. PND was sought by $38 \%$ of those deciding to marry, and all affected pregnancies were terminated [24]. A 5-year evaluation found that $98 \%$ of at-risk couples proceeded with marriage, with PND sought by $76 \%$ and 10 of the 11 affected pregnancies terminated. Thirty couples, married prior to 2008 with at least 1 thalassaemia-affected child, were offered PND and all 3 affected foetuses identified were aborted [4]. The number of thalassaemia-affected births in Kurdistan decreased from 20 to 7 over 5 years, a reduction of $65 \%$ [4].

Jordan

The PMSGC programme was mandated in Jordan in 2004. PND is legal, upon request on a self-pay basis, but therapeutic abortion is illegal. Oseroff [3] found that PMSGC discouraged $40 \%$ of at-risk marriages, while the demand for PND was low due to costs and unavailability of abortion. Hamamy and Al-Allawi [24] found that of 48 at-risk couples identified in 2006, only $3(6 \%)$ cancelled marriage plans. There were no findings in the literature regarding changes in $\beta$-thalassaemia incidence rates in Jordan.

\section{Saudi Arabia}

The national PMSGC programme, mandated in 2004, offers screening to all couples registered to marry. Couples found to be at risk receive counselling, as PND and therapeutic abortion are illegal [1]. Alhamdan et al. [20] reported a $10.4 \%$ at-risk marriage cancellation rate in 2004-2005. Alswaidi and O'Brien [10] reported a rate of $11.8 \%$ for 2005-2006 and Al Sulaiman et al. [21] reported a rate of $2 \%$, while Memish and Saeedi [1] found a rate of $26.5 \%$ in 2004-2009. An increasing at-risk marriage cancellation trend of $9.2 \%$ in 2004 to $51.9 \%$ in 2009 was found [1]. Alswaidi and O'Brien [10] reported that carriers with prior knowledge of their status were more likely to cancel marriage with another carrier than those without prior knowledge (11.8 vs. $28.8 \%$ cancellation rates, respectively). While Cousens et al. [12] reported that the incidence of $\beta$-thalassaemia has changed little in Saudi Arabia, statistics were not found in the literature reviewed. 
Turkey

PMSGC was mandated in Turkey in the 1990s (in Denizli from 1995 and in Mersin from 1998). PND and therapeutic abortion are legal. A 4-year evaluation in Denizli found a $13.3 \%$ marriage cancellation rate among at-risk couples while $40 \%$ sought PND, with 1 foetus diagnosed with $\beta$-thalassaemia and terminated [22]. Of 135 at-risk pregnancies in 1999-2004, 80 received PND and only 2 receiving PND delivered an affected baby, 1 due to a late referral [28]. A national review indicated that Turkey's PMSGC programme achieved a 90\% reduction in $\beta$-thalassaemia births annually, reducing from 272 births in 2002 to 25 in 2010 [25]. No analysis of changes in $\beta$-thalassaemia incidence rates in Turkey was found.

\section{Barriers and Enablers}

Literature on 6 countries (i.e. Bahrain, Iran, Iraqi Kurdistan, Jordan, Saudi Arabia and Turkey) discussed barriers and enablers of programme success $[1,4,10,12-$ 14, 19-27]. Analysis identified 7 emergent themes (table 4). Influences included culture and stigma (11 sources), religion (11 sources), thalassaemia awareness (10 sources), timing of the screening (7 sources), availability of PND and abortion (7 sources), PND costs (7 sources) and counsellor skills (4 sources).

\section{Bahrain}

A study of at-risk couples who decided to marry attributed their decisions to: (i) a low perceived risk, (ii) a low perceived seriousness of thalassaemia, as people can live a long time with the disease, (iii) fatalism and (iv) being informed of the availability of PND and therapeutic abortion during counselling rather than being discouraged to marry [23].

\section{Iran}

The Iranian PMSGC programme was associated with significantly reduced $\beta$-thalassaemia births, but the rates remained above zero as at-risk couples continued to marry and have children [10]. Major barriers described were marriage before programme initiation (51.4\%), cultural issues (15\%) and genetic counselling inadequacy (9\%) [19]. Karimi et al. [14] reported similar findings in Southern Iran, including marriages before programme implementation, culture and religion, and declined PND and abortion. Ahmadnezhad et al. [13] attributed the low PND uptake in West Azerbaijan to inaccessibility (e.g. if PND was not offered locally and couples needed to travel to the capital) and costs not covered by insurance.
Iraqi Kurdistan

The main barriers in Northern Iraq were identified as: (i) limited awareness of $\beta$-thalassaemia inheritance allowing high consanguineous marriage rates (24-27\%), (ii) distrust of test results (2\%), (iii) high user costs for PND, (iv) a short time between testing and marriage dates limiting cancellations and (v) social and cultural discomfort with marriage cancellation on short notice [24]. Religion apparently had a limited effect on selective termination decisions for the affected pregnancies [24].

Jordan

Major barriers to the success of the Jordanian programme included: (i) unregulated private laboratories (e.g. families could fabricate negative test results through personal connections if private laboratories accepted reports without testing to increase revenues) and (ii) exploitation of abortion rules (e.g. women with affected pregnancies could find 2 physicians, usually private-sector, to sign that the pregnancy posed a threat to her life) [3]. Abortion is thus essentially semi-legal, displaying the inadequacies of a programme that provides PND without providing legally sanctioned responses.

Reasons for fabricating results included the stigma of a carrier status, particularly for the bride and the family who were 'tainted' by a positive result, with potentially long-term effects on the marriageability of other women in the family. In nearly half of cases where the woman alone was a carrier, the husband left despite the non-existent risk of an affected child [3]. This indicates both gender disparities and a lack of accurate $\beta$-thalassaemia knowledge. Alswaidi and O'Brien [10] noted that many Jordanians considered the results of their union as fate, with one Jordan Times interviewee stating: 'All my ten children are disabled; they will get their reward in Heaven' $[3,10]$. Counselling was provided by general practitioners with minimal or no training in genetic counselling, leading to inadequate counselling provision and violation of the WHO PMSGC guidelines [3].

\section{Saudi Arabia}

Alswaidi and O'Brien [10] concluded that the main barriers to the Saudi PMSGC programme's success were: (i) completed non-cancellable wedding plans (43\%), (ii) fear of social stigma (21\%), (iii) familial commitment/ pressures (17\%) and (iv) religious considerations (14\%) [10]. Almost all couples were screened just before the wedding ceremony, and 52\% who proceeded to marry attributed their decision to wedding arrangements al- 
Table 4. Emergent themes per source, ordered by country and first author

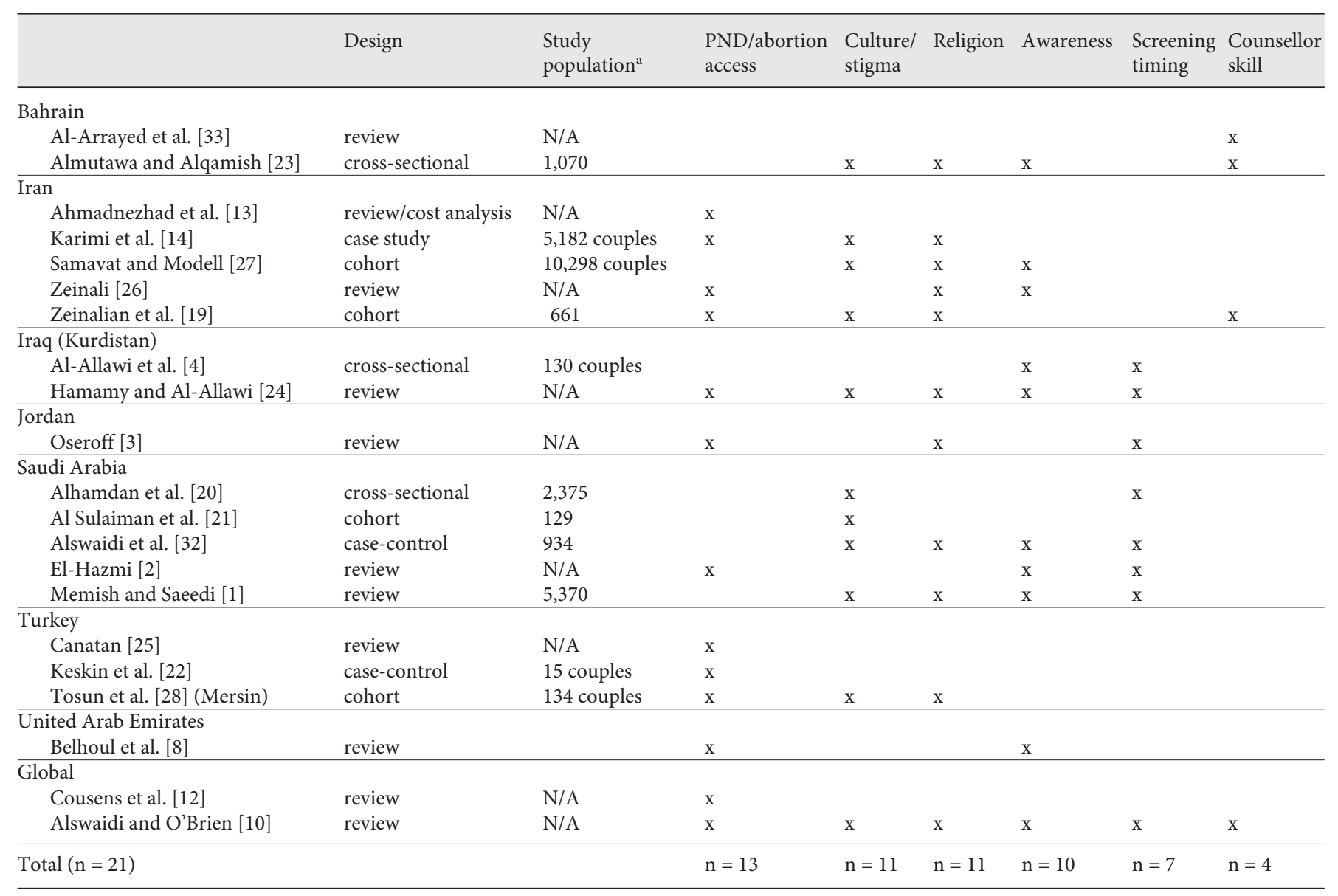

$\mathrm{x}=$ Data on this theme is included in the source; N/A = not applicable. ${ }^{\text {a }}$ Presented as numbers of individuals unless otherwise stated.

ready being made with cancellation not a viable option (e.g. after providing a new house and an expensive bride dowry). Alhamdan et al. [20] agreed that the late timing of screening was the major barrier to programme success given non-cancellable wedding plans. Premarital screening often comes too late for couples, who are already committed to their relationship. Two studies concluded that sociocultural pressures were among the main reasons at-risk Saudi couples proceeded with marriage $[1,21]$. Stigma associated with a carrier status, fear of publically declaring incompatibility, and a lack of education or awareness of hereditary diseases were additional barriers [20]. Religion was a barrier in some circumstances, as Islam teaches acceptance of fate and some interpret this as accepting the risk of a sick child. However, Islamic teaching promotes a healthy marriage and family, allowing scope for many interpretations fa- vouring the role of counselling [10]. Counsellors' inability to provide adequate information to at-risk couples was identified as a barrier [20]. However, Cousens et al. [12] concluded that the failure of the Saudi programme was primarily due to termination of the affected pregnancies being illegal.

\section{Turkey}

The availability of PND and therapeutic abortion were identified as crucial enablers for programme success in Turkey, as prevention based solely on screening and counselling produced no consistent effect on $\beta$-thalassaemia birth rates [25]. A study of barriers to PND usage found: (i) a lack of social security financing, (ii) insufficient knowledge of hereditary diseases (e.g. 15to 20-min counselling sessions could not provide adequate information) and (iii) culture [28]. 


\section{Discussion}

\section{Extent and Distribution of the Literature}

A scoping design was selected due to the minimal relevant literature expected. Gaps in extent and distribution include minimal literature comparing $\beta$-thalassaemia birth rates following mandatory PMSGC programme implementation, especially for Saudi Arabia, Bahrain and Jordan and none for the Palestinian Territories. Thus, it was not possible to fully ascertain programme impact.

\section{Effectiveness}

The success criteria used in this review were $65 \%$ reductions in at-risk marriages or $\beta$-thalassaemia births (table 3). None of the programmes reviewed achieved $65 \%$ reductions in at-risk marriages. Findings suggest that programmes in Saudi Arabia and Jordan have only achieved 10 and $40 \%$ reductions in at-risk marriage rates, respectively. Without legal therapeutic abortion, programmes will only succeed by separating carrier couples. Given the low marriage cancellation rates and that abortion remains illegal in these countries, it is unlikely that a large decrease in $\beta$-thalassaemia births could have occurred. Data on the reduction of $\beta$-thalassaemia births was unavailable for programmes in Bahrain, Jordan and Saudi Arabia, but programmes in Turkey, Iran and Iraqi Kurdistan achieved reductions in $\beta$-thalassaemia births of approximately 90,80 and $65 \%$, respectively (table 3 ).

The sole impact of premarital genetic testing in reducing the incidence of $\beta$-thalassaemia appeared minimal, as programmes lacking therapeutic abortion did not successfully reduce the numbers of $\beta$-thalassaemia births. Success was most evident in programmes including free PND and legal accessible therapeutic abortion $[3,4,13$, $24,28]$. As a comparison, less than $5 \%$ of the $100 \%$ success rates of programmes implemented in the Mediterranean region in the 1970s (table 3) was attributed to the separation of engaged at-risk couples [15].

\section{Barriers and Enablers}

The success of PMSGC programmes in Iran, Turkey and Iraqi Kurdistan was attributed to the availability of PND and therapeutic abortion. The main barriers to atrisk marriage cancellation were similar to those for seeking PND and therapeutic abortion (e.g. social unacceptability, lack of knowledge, access and costs). Thus, the increasing at-risk marriage cancellation rates noted in West Azerbaijan and Saudi Arabia may be due to in-

Review of Mandatory $\beta$-Thalassaemia Screening in the Middle East creased understanding of $\beta$-thalassaemia, while the decreasing cancellations in Central Iran and Iraqi Kurdistan may relate to an increased PND uptake and increased acceptability of PND and therapeutic termination.

\section{Life Cycle Approaches}

Life cycle or life course approaches provide a holistic framework for identifying health challenges and critical periods for intervention throughout the life cycle from preconception to death $[29,30]$. Findings indicated that adopting a life cycle approach to $\beta$-thalassaemia prevention, and intervening at critical periods during youth, premarital/preconception, prenatal and neonatal life stages, could be more successful than premarital screening alone [31]. Life cycle approaches provide a more holistic public health response, which can address barriers to programme success in the Middle East found in the literature (i.e. limited knowledge and awareness, nontimeliness of the screening directly before marriage and a lack of therapeutic abortion).

\section{Population}

Media campaigns could increase the knowledge and awareness of the risks and prevention of genetic diseases and consanguineous marriages. Two major barriers identified, i.e. fear of the stigma associated with a carrier status and familial pressures for consanguineous marriages, could be reduced through increased general understanding of the disorder [8]. Support from religious authorities, essential to encouraging programme acceptance, was found to be a major enabler in the Mediterranean region $[1,10,28]$.

Youth

$\beta$-Thalassaemia screening programmes should initially target people before marital and childbearing ages to allow more time to avoid or plan around high-risk marriages and births. Screening could be incorporated into school health packages (e.g. as in parts of India and Canada $[12,15])$, or required for university entry, along with health education on hereditary diseases and consanguineous marriages. While results from India indicated that school screening was insufficient alone, school health programmes appeared to be a feasible entry point for screening [15]. Conducting initial screening as part of a life cycle approach, well in advance of marital arrangements, would avoid barriers related to social commitments. Sources indicated that those with prior knowledge of their status were less likely to proceed with at-risk marriages $[4,32,33]$. 
Premarital/Preconception Period

Provision of genetic screening and counselling in government-regulated facilities for all couples wishing to marry remains essential. To be effective, counselling should be provided by trained professionals who can provide accurate advice regarding the risks and childbearing options.

\section{Prenatal Period}

PND and therapeutic abortion were described as particularly important in the available literature. The traditional stance on therapeutic abortion should be reviewed in light of legal precedents in Bahrain, Iran, Iraqi Kurdistan and Turkey allowing therapeutic abortion before 16 weeks of gestation for thalassaemia-affected foetuses. If therapeutic abortion is legalised, it is important that national policies ensure that PND is: (i) conducted as early in pregnancy as possible to enable completion of diagnostic testing before 16 weeks of gestation and (ii) subsidised by government or insurance schemes to be affordable and accessible for all population groups.

\section{Neonatal Period}

Appropriate support for those affected remains an important aspect of life cycle approaches. Thalassaemia-affected infants require considerable care. Couples married prior to PMSGC programme inception and still of childbearing age require screening. This could be done in a relatively nondisruptive way at antenatal service presentation if the father is present and adequate counselling for at-risk couples is provided. Couples with a thalassaemiaaffected child require both support and counselling regarding options for future pregnancies.

\section{Limitations}

A limitation of reviews is not capturing all relevant sources. Reviewing the literature in English may have excluded important publications in Arabic. However, screening of translated abstracts should have captured most such publications. Scoping reviews do not evaluate the quality of sources, and discussion of programme effectiveness should be interpreted accordingly. However, they are most appropriate for topics such as this with little published literature available.

\section{Conclusions}

PMSGC programmes were unsuccessful at discouraging at-risk marriages, primarily due to poor timing of the premarital screening, a lack of knowledge regarding inherited diseases, and sociocultural and religious concerns. Programmes that significantly reduced $\beta$-thalassaemia births (e.g. Iran, Iraqi Kurdistan and Turkey) did so through accessible PND and therapeutic abortion. The lack of $100 \%$ reductions appeared to be due to cultural and awareness barriers. Comprehensive $\beta$-thalassaemia prevention (e.g. life cycle approaches) would likely be more effective than PMSGC alone in reducing the prevalence of $\beta$-thalassaemia in the Middle Eastern region.

\section{Acknowledgements}

We acknowledge all of the authors of the included sources. Thanks to the stakeholders for reviewing a draft of the findings.

\section{References}

-1 Memish ZA, Saeedi MY: Six-year outcome of the national premarital screening and genetic counseling program for sickle cell disease and beta-thalassemia in Saudi Arabia. Ann Saudi Med 2011;31:229-235.

-2 El-Hazmi MA: The natural history and the national pre-marital screening program in Saudi Arabia. Saudi Med J 2004;25:1549-1554.

3 Oseroff B: The Ethics of Prevention: Counselling, Consanguinity, and Premarital Testing for Beta-Thalassemia in Jordan. Princeton, Princeton University, 2011.

4 Al-Allawi NA, et al: The first five years of a preventive programme for haemoglobinopathies in Northeastern Iraq. J Med Screen 2013; 20:171-176.
5 Habibzadeh F: Thalassaemia in the Middle East. Lancet (Middle East Ed) 2012, p 379.

-6 Lahiry P, Al-Attar S, Hegele R: Understanding $\beta$-thalassemia with focus on the Indian subcontinent and the Middle East. Open Haematol J 2008;2:5-13.

7 Sattari M, et al: The financial and social impact of thalassemia and its treatment in Iran. Pharm Sci 2012;18:171-176.

8 Belhoul KM, Abdulrahman M, Alraei RF: Hemoglobinopathy carrier prevalence in the United Arab Emirates: first analysis of the Dubai Health Authority premarital screening program results. Hemoglobin 2013;37:359368.
9 Al-Gazali L, Hamamy H, Al-Arrayad S: Genetic disorders in the Arab world. BMJ 2006; 333:831-834

10 Alswaidi FM, O’Brien SI: Premarital screening programmes for haemoglobinopathies, HIV and hepatitis viruses: review and factors affecting their success. J Med Screen 2009; 16: 22-28.

11 Hamamy H: Consanguineous marriages: preconception consultation in primary health care settings. J Community Genet 2012;3: 185-192.

12 Cousens NE, et al: Carrier screening for $\beta$-thalassaemia: a review of international practice. Eur J Hum Genet 2010;18:10771083. 
13 Ahmadnezhad E, et al: Evaluation and cost analysis of national health policy of thalassaemia screening in West-Azerbaijan Province of Iran. Int J Prev Med 2012:3:687-692.

14 Karimi M, et al: Premarital screening for $\beta$-thalassaemia in Southern Iran: options for improving the programme. J Med Screen 2007;14:62-66.

15 Petrou M: Screening for beta thalassaemia. Indian J Hum Genet 2010;16:1-5.

$\checkmark 16$ Hedayat K: When the spirit leaves: childhood death, grieving, and bereavement in Islam. J Palliat Med 2006;9:1282-1291.

17 Arksey H, O’Malley L: Scoping studies: towards a methodological framework. Int J Soc Res Methodol 2005;8:19-32.

$\checkmark 18$ Levac D, Colquhoun H, O’Brien KK: Scoping studies: advancing the methodology. Implement Sci 2010;5:69.

19 Zeinalian M, et al: Two decades of pre-marital screening for beta-thalassemia in Central Iran. J Community Genet 2013;4:517-522.

20 Alhamdan NA, et al: Premarital screening for thalassemia and sickle cell disease in Saudi Arabia. Genet Med 2007;9:372-377.
21 Al Sulaiman A, et al: Postmarital follow-up survey on high risk patients subjected to premarital screening program in Saudi Arabia. Prenat Diagn 2010;30:478-481.

22 Keskin A, et al: Premarital screening of $\beta$-thalassemia trait in the province of Denizli, Turkey. Acta Haematol 2000;104:31-33.

23 Almutawa F, Alqamish J: Outcome of premarital counseling of hemoglobinopathy carrier couples attending premarital services in Bahrain. J Bahrain Med Soc 2009;21:217-220.

24 Hamamy HA, Al-Allawi NA: Epidemiological profile of common haemoglobinopathies in Arab countries. J Community Genet 2013; 4:147-167.

25 Canatan D: Hemoglobinopathy prevention program in Turkey. Abstracts 12th Int Conf Preimplantation Genet Diagn. Istanbul, 2013.

26 Zeinali S: Progress in reduction of new cases of thalassemia as a result of a communitybased preventive program in Iran. Abstracts 12th Int Conf Preimplantation Genet Diagn. Istanbul, 2013.

27 Samavat A, Modell B: Iranian national thalassaemia screening programme. BMJ 2004; 329:1134-1137.
28 Tosun F, et al: Five year evaluation of premarital screening program for hemoglobinopathies in the province of Mersin, Turkey. Turk J Haematol 2006;23:84-89.

29 Ben-Shlomo Y, Kuh D: A life course approach to chronic disease epidemiology: conceptual models, empirical challenges and interdisciplinary perspectives. Int J Epidemiol 2002;31: 285-293.

30 Kuh D, et al: Life course epidemiology. J Epidemiol Community Health 2003;57:778-783.

31 El-Hazmi MA: Ethics of genetic counseling basic concepts and relevance to Islamic communities. Ann Saudi Med 2004;24:84-92.

-32 Alswaidi FM, et al: At-risk marriages after compulsory premarital testing and counseling for $\beta$-thalassemia and sickle cell disease in Saudi Arabia, 2005-2006. J Genet Couns 2012;21:243-255.

$33 \mathrm{Al}$ Arrayed S: Campaign to control genetic blood diseases in Bahrain. Community Genet 2005;8:52-55.

34 United Nations: World Abortion Policies 2013. Geneva, UN, 2013. 